\title{
Epinephrine infusion during urgent appendectomy in a 39 years old patient with aggresive systemic mastocytosis: a case report.
}

\section{Maliamanis Dimitrios¹,Douma Amalia², Spyrou Andriana², Nixon Alexander ${ }^{3}$, Brozou Vassiliki ${ }^{2}$, Kalogeromitros Alexander ${ }^{1}$}

${ }^{1}$ Anaesthesiologist, ICU "G.Gennimatas" Athens General Hospital, ${ }^{2}$ Anaesthesiologist, Department of Anaesthesia "G.Gennimatas" Athens General Hospital, ${ }^{3}$ Surgeon, 3dDepartment of Surgery

"G.Gennimatas" Athens General Hospital

Background: Systemic mastocytosis is a rare disorder, with symptoms and signs related to mast cell (MC) degranulation such as urticaria, flushing, pruritus, dyspnea and anaphylaxis. Symptoms can be triggered by drugs, mechanical stimuli and stress or even induced spontaneously ${ }^{1}$.

Case report: A 39 years old female was presented for urgent laparotomy because of ruptured appendix and peri-appendicular abscess, shown at CT scan. She had a history of severe systemic mastocytosis and reported multiple anaphylactic episodes per year treated with epinephrine. Preoperatively, $\mathrm{H} 1$ and $\mathrm{H} 2$ antagonists (dimethindene $0.1 \mathrm{mg} / \mathrm{kg}$ and ranitidine $50 \mathrm{mg}$, respectively), hydrocortisone 500 $\mathrm{mg}$ and midazolam $2 \mathrm{mg}$ have been administered. After induction of anaesthesia with fentanyl $3 \mu \mathrm{g} / \mathrm{kg}$, propofol $2.5 \mathrm{mg} / \mathrm{kg}$ and cis-atracurium $0.2 \mathrm{mg} / \mathrm{kg}$ and successful intubation, rash at the site of injection and the thorax was noticed, followed by hypotension, tachycardia and bronchospasm. Anaphylaxis protocol was followed. A bolus intravenous dose of epinephrine $1 \mu \mathrm{g} / \mathrm{kg}$ was administrated, followed by continuous infusion of epinephrine $0.04 \mu \mathrm{g} / \mathrm{kg} / \mathrm{min}$ to maintain arterial pressure within normal range ${ }^{3}$. The patient was stabilized and the team decided to proceed with the operation under sevoflurane and remifentanil infusion. At the end of the operation, the patient was extubated uneventfully and transferred to ICU

Discussion: Prophylactic premedication decreases the probability of suffering perioperative MC degranulation symptoms, particularly when $\mathrm{H} 1 / \mathrm{H} 2$ antihistamines and benzodiazepines are included, although the risk of anaphylaxis is higher with major surgery and general anaesthesia ${ }^{1,2}$. Complete allergic work-up and serum tryptase levels are mandatory but cannot be determined on urgent basis. Recommendations on intraoperative management of anaphylaxis consist of intramuscular doses of epinephrine ${ }^{2}$ or continuous infusion $(0.05-0.1 \mu \mathrm{g} / \mathrm{kg} / \mathrm{min})$, if repetitive doses are needed ${ }^{3}$. In this case, after the initial dose, an early epinephrine infusion tailored to patient's needs was decided, in order to preserve cardiovascular stability.

Learning points: Anaphylaxis can be seen in a patient with systemic mastocytosis even after prophylactic premedication. In any case, treatment should start early and should be individualized.

\section{References:}

-1.Matito et al. Manag of anesth in adult and ped mastocytosis: a study of the Spanish Network on Mastocytosis. Int Arch Allergy Immunol. 2015;167:47e56

-2.Hermans et al. Management around invasive procedures in mastocytosis: An update. Ann. Allergy Asthma Immunol. 2017 Oct;119(4):304-309

-3.Kroigaard et al. Scand Guidelines on anaphylaxis during anaesth. Acta Anaesthesiol Scand 2007; 51:655-70 